\title{
Impact of evaluative criteria on satisfaction and dissatisfaction: identifying the role of knitwear involvement
}

\author{
So Won Jeong ${ }^{1}$ and Kyu-Hye Lee $2^{2^{*}}$
}

* Correspondence:
khlee@hanyang.ac.kr
²Department of Clothing and
Textiles, Hanyang University, 222
Wangsimni-ro, Seongdong-gu,
Seoul 133-791, Korea
Full list of author information is
available at the end of the article

available at the end of the article

\begin{abstract}
This research explores an impact of evaluative criteria on consumer responses to knitwear products (satisfaction and dissatisfaction). Two conceptual frameworks are developed to identify the role of knitwear involvement as an antecedent of evaluative criteria and as a moderator between evaluative criteria and consumer responses. The survey was administered with a total of 382 Korean consumers. Structural equation modeling was employed to test the proposed hypotheses. The results confirmed the significant effects of knitwear involvement as an antecedent as well as a moderator on evaluative criteria, satisfaction, and dissatisfaction. Differential influences of evaluative criteria on satisfaction and dissatisfaction are shown. Theoretical and managerial implications are discussed.
\end{abstract}

Keywords: Knitwear; Involvement; Evaluative criteria; Satisfaction; Dissatisfaction

\section{空

\section{Introduction}

Since 2005, Korean apparel market has been recovering from the recession period, reaching to 24.5 trillion dollars of the apparel market size of Korea in 2009 (KAIA 2010). As a public interest in recreational activities and health is growing, the demand for knitwear products is also increasing (Hong et al. 2002). According to the recent report of KAIA (Korean Apparel Industry Association 2010), the amount of consumed and imported knitwear products is increasing as a $6.6 \%$ consumption growth and a $3.7 \%$ import growth while the amount of produced and export knitwear products is decreasing as a $7.2 \%$ production decline and a 12.8\% export decline between 2005 and 2009. The previous research relevant to knitwear products in Korean apparel market includes the analysis of knitwear designer's artworks, knit patternmaking, knit brand, attribute evaluation, and consumption pattern (Han and Kim 2000; Lee et al. 2007). Regarding the emerging demand of knitwear, there is a clear need to explore consumer evaluation process of knitwear products.

Evaluative criteria are important to understand consumer evaluation process and choices (Forney et al. 2005). Eckman et al. (1990) suggest that researchers need to examine the effect of multiple criteria at making purchase decision as the cognitive process of product evaluation. They can provide valuable information to manufacturers and marketers because they reflect underlying consumer values, attitudes, knowledge, 
experience, and various psychological, sociological, and economic influences (Forney et al. 2005). Evaluative criteria vary by purchase situation (Dickson 1982), the nature of alternatives evaluated (Corfman 1991), involvement level (Gensch and Javagli 1987), knowledge level (Lee and Park 2006a), age (Han and Kim 2000), and ethnicity (Jin et al. 2010).

Involvement has frequently been discussed with consumer attitudes or evaluations in prior research (Lee and Park 2006a; Swoboda et al. 2009). Involvement is an important issue in fashion apparel because it describes a symbolic consumption area for consumers (O'Cass 2000). Individuals purchase clothing for more than functional performance (e.g., warmth or protection), for example, to express their social status and personality. How involved consumers become in their clothing provides understanding of the dynamics of consumer behavior (O'Cass 2000); involvement of an individual affects both emotional and cognitive processes (Park et al. 2007b). Though influence of involvement on consumer behavioral dynamics is confirmed, there is still a lack of consensus in determining the role of involvement. Involvement has been found as an antecedent, for example, a variable influencing knowledge and evaluative criteria (Lee and Park 2006a) and having a positive effect on perception of brand status and brand attitude (O'Cass and Choy 2008). However, involvement has also been discusses as a moderator, for instance, a variable influencing the relationships between perceived retailer attributes and retailer brand equity (Swoboda et al. 2009) and between customer satisfaction and loyalty (Suh and Yi 2006). Thus, there is a need to investigate the role of involvement as both a moderator and an antecedent, a mediator, and to examine which one better explains the role of involvement.

Regarding product attribute evaluation, especially for knitwear, Han and Kim (2000) studied knitwear evaluation criteria with information searching behavior when buying knitwear. Park et al. (2007a) also examined differences in knit product evaluation criteria according to consumer gender, age, and interest and their purchasing behavior. However, there is little research on knitwear involvement and attribute evaluation or evaluative criteria in Korean apparel market. Lee and Park (2006a) examined product attribute evaluation criteria with objective knowledge, subjective knowledge, and apparel involvement of Korean consumers, but they examined a general category of clothing, not focused on a specific category of clothing, for example, knitwear.

Regarding the continuous demand and importance of knitwear market in Korean apparel industry, there is a clear need to examine product evaluation criteria, especially for knitwear products. In the previous literature, involvement was found as one of the most influential variable to explain product evaluation or evaluative criteria (Lee and Park 2006a; Swoboda et al. 2009). Thus, knitwear involvement was specifically investigated in the present study to identify the role of consumer involvement in explaining product evaluative criteria. Also, considering the dearth of an itemized study especially in the knitwear segment, an endeavor to explore the relationships among knitwear involvement, evaluative criteria, and consumer responses will enhance our understanding of consumer behavior in the knitwear context. In addition, regarding the lack of consensus in role of involvement, there is a need to examine the role of involvement as an antecedent and a moderator. Accordingly, the purpose of this study is to identify the role of knitwear involvement on evaluative criteria and consumer responses (e.g., satisfaction and dissatisfaction) to knitwear products. To accomplish this purpose, two 
models are tested employing involvement variable as an antecedent and a moderator. First, a theoretical framework is developed to examine knitwear involvement as an antecedent of evaluative criteria, satisfaction, and dissatisfaction. Second, knitwear involvement is examined as a moderator affecting the relationships among evaluative criteria, satisfaction, and dissatisfaction.

\section{Literature review}

\section{Knitwear involvement}

Involvement refers to "a construct linked to the interaction between an individual and an object" or "the relative strength of the consumers' cognitive structure related to a focal object (e.g., products)" (O'Cass 2000). In the context of fashion, involvement is defined as "the extent to which the consumer views the related fashion activities as central part of their life" (O'Cass and Choy 2008, p. 342). Previous literature discussed the existence of various types of involvement (O'Cass and Choy 2008). Consumers can be involved in various objects such as products, advertisements (or communication) for the product, purchase decision, consumption, and brand decision (O'Cass 2000; O'Cass and Choy 2008). O'Cass (2000) proposed four types of involvement; product involvement, purchase decision involvement, advertising involvement, consumption involvement, and a higher order construct of these four, called consumer involvement. Involvement can also be classified as either situational or enduring (Huang 2006; Lee et al. 2005). Involvement with the product has been classified as enduring in nature (Mittal 1989), but O'Cass (2000) noted that the degree of the involvement changes as a result of interaction with a stimulus or the environment, which can be classified as situational (O'Cass 2000). In the present study, to focus on a consumer-knitwear relationship, knitwear involvement refers to the overall profile of involvement in knitwear products perceived by consumers, which is enduring, not changing by a situation or environment in a short period of time.

\section{Evaluative criteria}

When comparing and assessing alternatives, consumers use evaluative criteria as the specifications or standards to make a decision (Forney et al. 2005). Evaluative criteria are defined as "the particular dimensions or attributes that are used in judging the choice alternatives" (Engel et al. 1995, p. 208). Clothing researchers frequently examined evaluative criteria (Eckman et al. 1990). Their categories and classifications vary by a purchase situation (Dickson 1982), the nature of alternatives evaluated (Corfman 1991), involvement level (Gensch and Javagli 1987), and individual differences and environmental influences (Eckman et al. 1990). Evaluative criteria previously examined by researchers include price, style, quality, design, size/fit, color, fabric, coordination with other clothing, comfort, pattern, pleasantness to others, appropriateness, brand name, and country of origin (Eckman et al. 1990; Hsu, and Burns 2002; Jin et al. 2010; Lee and Park 2006a; Ong et al. 2010).

However, there are common factors measuring evaluative criteria across products, consumers, and retail stores. Previous research classified evaluative criteria as intrinsic and extrinsic. Intrinsic cues refer to "product attributes that cannot be changed or manipulated without also changing the physical characteristics of the product itself" such as product composition, performance, quality and sex appropriateness (Eckman et al. 
1990, p. 14). Extrinsic cues are "product attributes that are not component parts of the physical product but that are applied by the manufacturer of retailer" such as price, brand, country of origin, coordination and stores (Eckman et al. 1990, p. 14). Eckman et al. (1990) classified intrinsic criteria used for making garment purchase decisions into aesthetic criteria, usefulness criteria, and performance and quality with extrinsic criteria. They found aesthetic criteria (i.e., color/pattern, styling, fabric, uniqueness, and appearance) as the most important for apparel assessment. Fiore and Damhorst (1992) also discussed the importance of the evaluative criteria relevant to aesthetics to determine the overall quality of women's pants. Lee and Burns (1993) identified evaluative criteria used in clothing purchase decision as three categories fashion and attraction (aesthetic criteria), quality (performance criteria), and brand name (extrinsic criteria) and revealed the significant relationship between the personal trait of selfconsciousness and attitudes toward clothing purchase criteria. Forney et al. (2005) identified the dimensions of evaluative criteria used when purchasing the extended brands of casual apparel and home furnishings as four; image, quality, color/style, and design/beauty. Their findings revealed that image was the strongest predictor of purchase decision of the brand extension when brands are extended from apparel to home furnishing products (Forney et al. 2005). Lee and Park (2006a) examined evaluative criteria with consumer knowledge and apparel involvement. They identified evaluative criteria as three dimensions depending on the characteristics of apparel attributes; intrinsic, social, and economic. In their study, the attributes of intrinsic criteria included design, color, fit, fabric, and comfort that were not changeable in terms of the physical characteristics of the product itself. They divided extrinsic criteria into two dimensions, social and economic criteria with the empirical supports. Social criteria were composed of the attributes that can be influenced by social judgments such as model, advertising, country-of-origin, and brand name. Economic criteria referred to the attributes relevant to a pursuit for economic benefits such as discount and price. In the present study, three dimensions of evaluative criteria suggested by Lee and Park (2006a) are used because their classification of social and economic criteria better reflect the characteristics of Koreans when evaluating apparel products than the other research employing the Western sample. Also, these criteria are also applicable to explain consumer evaluation of knitwear products. Thus, to examine the evaluative criteria of knitwear, the current research employed the dimensions developed by Lee and Park (2006a). To explore the relationships between evaluative criteria and consumer responses (i.e., satisfaction and dissatisfaction), the importance placed on evaluative criteria by consumers is investigated in the study following Fiore and Damhorst (1992) and Hsu and Burns (2002), because evaluative criteria constructs reflect consumers' perceived importance of each evaluative criteria (i.e., intrinsic, social, and economic criteria) in judging the choice alternatives.

\section{Satisfaction and dissatisfaction}

Consumer satisfaction and dissatisfaction is the psychological response to fulfillment of expectation of product after purchase (Day 1984). Consumer satisfaction and dissatisfaction are defined as "an emotional response manifested in feelings and is conceptually distinct from cognitive responses, brand affect, and behavioral responses" (Day, 1983, p. 113). While satisfaction was frequently studied as a variable to assess consumer 
response (Oliver 1997; Yi 1990), dissatisfaction received relatively little attention in consumer research (Giese and Cote 2000). Accordingly, Giese and Cote (2000) suggested that there are two approaches to conceptualizing the dissatisfaction construct; consumer dissatisfaction as the bipolar opposite of satisfaction (completely satisfied/very dissatisfied) (Mittal et al. 1999) vs. consumer dissatisfaction as a separate dimension from satisfaction, using unipolar satisfaction and dissatisfaction measures (Mano and Oliver 1993; Westbrook and Oliver 1991). For dissatisfaction, the literature does not provide a clear conceptualization, but dissatisfaction is regarded as usually more extreme, occurring sooner, and lasting longer than satisfaction (Giese and Cote 2000). Also, consumers can be satisfied with one attribute or experience, but dissatisfied with another (Giese and Cote 2000). Previous research on knitwear found that consumers were satisfied with design, color, styling, comfort, fit, quality and coordination with their wardrobe, but dissatisfied with pilling problem, durability, laundering properties or retention of shape (Swan and Combs 1976). Adopting Giese and Cote's discussion (Giese and Cote 2000), the present study distinguish satisfaction from dissatisfaction and employ two unipolar variables of satisfaction and dissatisfaction to effectively assess consumer responses to knitwear products.

\section{Influence of evaluative criteria on satisfaction and dissatisfaction}

Previous literature discussed the influence of evaluative criteria or attribute evaluation on consumer responses such as satisfaction and dissatisfaction (Park 2012; Yeo and Rhee 1996). Evaluative criteria may not play a critical role in purchase decision, but enhance satisfaction and likelihood to buy (Eckman et al. 1990). For example, consumers may reject the pants if those fit and appearance are not evaluated as satisfactory (Eckman et al. 1990). Park (2012) examined the purchase appraisal standard and postpurchase satisfaction of natural dyeing products. Research findings indicated that product attributes such as product quality, kinds of item, color change, and product lifespan affected post-purchase satisfaction. Yeo and Rhee (1996) examined the decision making procedure of consumer's post purchase for social daytime wear. In their study, postpurchase clothing evaluative criteria (e.g., fit, utility, management, transformation, and wearing/sewing) were found as important antecedents of satisfaction and brand attitude. Further, satisfaction positively affected brand attitude, and both satisfaction and brand attitude positively influenced repurchase intention.

\section{Involvement as an antecedent of evaluative criteria, satisfaction, and dissatisfaction}

Given that involvement reflects the relevance, value, interest, or need that consumer has in product, it is an important element to define and assess dimensions of product evaluation (Mano and Oliver 1993). O'Cass and Choy (2008) investigated the effect of fashion clothing involvement of young Chinese as an antecedent on specific brand related responses. They found that a consumer's fashion clothing involvement represented by two factors of fashion clothing product involvement and fashion clothing purchase decision involvement positively affected consumer's perception on brand status and brand attitude. Chae et al. (2006) examined the relationship among prepurchase and post-purchase satisfaction and fashion involvement of women who participated in a tennis tournament by employing the Engel, Blackwell, and Miniard model on consumer decision making. They found a positive relationship between fashion involvement and satisfaction. Among clothing attributes, comfort and fit were important for 
women to achieve satisfaction before and after their purchase. Tsiotsou (2006) examined the effects of perceived product quality (an element of intrinsic criteria) and overall satisfaction on purchase intentions using sport shoes products. Findings showed a direct and an indirect effect of perceived quality on purchase intentions through overall satisfaction and a direct effect of overall satisfaction on purchase intentions. Involvement was found as an antecedent of perceived product quality and as having its indirect effect on purchase intentions through perceived quality and overall satisfaction. Lee and Park (2006a) revealed a significant, positive effect of apparel involvement as an antecedent on product evaluation criteria, evaluation of intrinsic, social, and economic attributes. In their study, consumer involvement was measured by interest in clothing, symbolic importance of clothing, and sensitivity to clothing trend perceived by consumers. The result found that consumers with a higher interest in apparel product but not in trends considered intrinsic attributes more importantly; consumers who pursue for latest trends considered social attributes more importantly; consumers who want to express their self-image but not to pursue for trends considered economic attributes more importantly.

Hypothesis 1: Knitwear involvement will positively influence evaluative criteria (H1a: intrinsic criteria, H1b: social criteria, H1c: economic criteria).

Hypothesis 2: Evaluation criteria (H2a: intrinsic criteria, H2b: social criteria, H2c: economic criteria) will positively influence consumer satisfaction with knitwear.

Hypothesis 3: Evaluation criteria (H3a: intrinsic criteria, H3b: social criteria, H3c: economic criteria) will negatively influence consumer dissatisfaction with knitwear.

\section{Involvement as a moderator of the links among evaluative criteria, satisfaction, and dissatisfaction}

Involvement was frequently examined as a moderator to determine purchase decisions (Celsi \& Olson, 1988). Swoboda et al. (2009) examined a moderating role of involvement in building a retail brand. They employed consumer sample spread over five retail sectors (grocery, clothing, DIY, electronics, and furniture). Using multi-group structural equation modeling, they found differential influences of the perceived retailer attributes on consumer response, brand equity depending on the involvement level of customers; service and assortment had a greater effect on retail brand equity in the low involvement group; price/value-ratio, communication, and store design had a greater effect on retail brand equity in the high involvement group. Lee and Park (2006b) examined differences of clothing criteria (esthetic, quality performance, and extrinsic criteria) and web service criteria (reliability, product assortment, easiness of transaction, satisfaction, and promotion and policy) of consumer groups depending on their involvement and Internet use ability levels. Four groups identified by high and low consumer involvement and high and low Internet use ability differed in their evaluations of esthetic, quality performance, and extrinsic criteria. Both high-involvement and high-ability group and high-involvement and low-ability group were found to consider every evaluation criterion of clothing more important than the other groups. Regarding web service evaluation, both high-involvement and high-ability group and high-involvement and low-ability group considered every criterion more important than the other groups. Especially, in terms of clothing product evaluation criteria, the level of the consumer involvement factor appeared as more important than the ability factor. Consumers highly involved in clothing were found as feeling more risk in purchasing clothing products and 
taking various clothing evaluation criteria into more consideration than those who are lowly involved in clothing. Suh and Yi (2006) also found a moderating role of product involvement in the relationship between customer satisfaction and loyalty toward a large household goods and cosmetics company. Product involvement was found to decrease the direct effects of satisfaction on brand attitudes and loyalty, while to increase the indirect effects of ad attitudes and corporate image. Since there is little study to examine the moderating role of involvement in the relationships among evaluative criteria, satisfaction, and dissatisfaction, based on the previous discussion, involvement is hypothesized to play a moderating role in evaluative criteria-satisfaction and evaluative criteria-dissatisfaction relations. Accordingly, the following hypotheses are proposed.

Hypothesis 4: Knitwear involvement will moderate the relationships among evaluative criteria, satisfaction, and dissatisfaction (H4a: intrinsic criteria - satisfaction, H4b: social criteria - satisfaction, H4c: economic criteria - satisfaction, H4d: intrinsic criteria - dissatisfaction, H4e: social criteria - dissatisfaction, H4f: economic criteria - dissatisfaction).

\section{Method}

\section{Measures}

The present study employed multiple-item measurement scales, validated and found to be reliable in previous research. A survey questionnaire was developed and modified from the original measurement items for the empirical study, which consists of knitwear involvement, intrinsic criteria, social criteria, economic criteria, satisfaction, and dissatisfaction. Knitwear involvement, defined as consumers' perceived involvement in knitwear, was measured by four items (interest in knitwear products, importance of knitwear products to respondents, felt enjoyment when coordinating various knitwear products, and interest in knitwear store or advertisement) adopted from Lee and Park (2006a) and O'Cass and Choy (2008). Three types of evaluative criteria measures were adopted from Eckman et al. (1990) and Lee and Park (2006a) and the importance placed on evaluative criteria was rated; 6 items for intrinsic criteria (design, color, fabric, comfort, fit, and workmanship), 4 items for social criteria (advertising, model, country-of-origin, and brand); 2 items for economic criteria (discount and price). Satisfaction and dissatisfaction scale items were adopted from Hong et al. (2002); 13 satisfaction items (satisfaction with design, color, comfort, combination, quality, size, absorption, fabric, price, service, care, fit, and trend) and 10 dissatisfaction items (dissatisfaction with lint, retention of shape after laundry, snag, care, size change, static electricity, color change, poor workmanship heat-retaining, and weight). All the items were revised and modified to be appropriate for the present study. The items were rated on a 5 -point Likert-type scale with anchors of "strongly disagree" as 1 and "strongly agree" as 5. Finally, demographic information (age, gender, marriage status, education, occupation, and monthly household income) and information about each participant's spending expenditure on clothing were collected.

\section{Results}

Sample

Data collection was performed using a quota sampling method based on gender and age. Survey was administered to consumers between their twenties and fifties who live in downtown, Seoul, Korea. The final sample size was 382 out of 463 after deleting missing data, resulting in a $83 \%$ response rate. Female respondents were $55 \%$. Average 
age of the respondents was 37.08. About 33\% of the respondents were between 18 and 29 years old, $24.5 \%$ between 30 and 39 years old, $21.3 \%$ between 40 and 49 years old, $20 \%$ between 50 and 59 years old, and 1.3\% between 60 and 70. Over half of the sample (56.4\%) was married and over $80 \%$ of respondents were college educated or higher. About $23 \%$ were student; $17.5 \%$ were office workers; $16.5 \%$ were professionals; $13.4 \%$ were housekeepers. About 20\% earned between 3,000,000 won and 4,000,000 won in a month; $17 \%$ earned between 2,000,000 won and 3,000,000 won; $14 \%$ earned between 1,000,000 won and 2,000,000 won; $12 \%$ earned between 4,000,000 won and 5,000,000 won. About a third of the respondents (31.9\%) spent between 100,000 and 200,000 won on clothing; $25.1 \%$ spent between 50,000 won and 100,000 won; $16.5 \%$ spent between 200,000 won and 300,000 won.

\section{Analyses}

Two conceptual frameworks are employed to identify the role of knitwear involvement as an antecedent and as a moderator. The measurement model was tested with one full sample model. Hypotheses $1-3$ were examined using a conceptual framework 1 . To identify the moderating role of knitwear involvement, a conceptual framework 2 tested hypothesis 4 with a two-group model employing the high and low knitwear involvement subgroups. Confirmatory factor analysis (CFA) and structural equation modeling (SEM) were conducted using AMOS 20 with the maximum likelihood estimation method. Before performing CFA, exploratory factor analysis (EFA) using a principal axis factoring method with varimax rotation was performed to refine the measures. An eigenvalue of 1.00 or greater was used for determining the number of factors to be extracted in the factor analysis. Eigenvalue and variance extracted for each variable were as follows: 3.18, 8.15\% for knitwear involvement, 2.80, 7.19\% for intrinsic criteria, 1.50, 3.85\% for social criteria, 1.25, $3.20 \%$ for economic criteria, $4.30,11.01 \%$ for satisfaction, and $6.20,15.89 \%$ for dissatisfaction, respectively. For construct validity, the measurement items with a factor loading below 0.50 (Arnold and Reynolds 2003) and above 0.30 for the other factors (Kleine 1998) were deleted; 6 satisfaction items (satisfaction with absorption, price, service, care, fit, and trend) and 2 dissatisfaction items (dissatisfaction with heat-retaining and weight).

CFA was performed to test the measurement model. To assess reliability and convergent and discriminant validity, a two-step approach suggested by Anderson and Gerbing (1988) was used. First, the measurement model was assessed for convergent and discriminant validity, and then the measurement model was respecified to purify measurements. Based on the CFA results and Anderson and Gerbing (1988), problematic indicators were deleted for the measurement model respecification. Items were deleted when they had significantly lower item reliability than that of the other items posited to measure the underlying construct, showed insignificant path coefficients for the construct, showed large residuals with other indicators, shared a large amount of variance with other indicators, or shared common variance with indicators posited to measure other constructs. As a result of scale purification processes, the following items were additionally deleted; one intrinsic criteria item (fit), one social criteria item (country-of-origin), two satisfaction item (satisfaction with quality and color), and three dissatisfaction items (dissatisfaction with static electricity, color change, and poor workmanship). After deleting problematic scale items, acceptable fit $(\chi 2=446.31, \mathrm{df}=237 \quad(\mathrm{p}<.001), \mathrm{RMR}=.03$, $\mathrm{CFI}=.94$, RMSEA $=.05$ ) was achieved (Hair et al. 2009). Convergent and discriminant 
validity were confirmed with composite reliability above .60, average variance extracted (AVE) above .50, and AVE estimates larger than the corresponding squared correlation estimates between two constructs (Bagozzi and Yi 1988).

For the first conceptual framework, SEM was used to test hypotheses $1-3$. The fit indices suggested that the model had an acceptable fit to the data $(\chi 2=510.91, \mathrm{df}=243$ $(\mathrm{p}<.001), \mathrm{RMR}=.04, \mathrm{CFI}=.92$, RMSEA $=.05)$. The Chi-square test was significant, but when the sample size is more than 250, it is usual to have a significant $p$-value (Hair et al. 2009). All coefficients for the paths were significant except for the paths from knitwear involvement to economic criteria, from social criteria to satisfaction, and from economic criteria to satisfaction and dissatisfaction. Figure 1 depicts the results of the SEM hypothesis testing $(\mathrm{H} 1-\mathrm{H} 3)$. Hypothesis 1 proposed that knitwear involvement positively influences evaluative criteria (H1a: intrinsic criteria, H1b: social criteria, H1c: economic criteria). Only H1a (intrinsic criteria) and H1b (social criteria) were supported ( $\beta=.42, t=6.94, p<.01 ; \beta=.18, t=3.12, p<.01$, respectively). H1c (economic criteria) was not supported $(\beta=.07, t=.94, p=.35)$. Hypothesis 2 proposed that evaluation criteria (H2a: intrinsic criteria, H2b: social criteria, H2c: economic criteria) positively influence consumer satisfaction with knitwear. Only $\mathrm{H} 2 \mathrm{a}$ (intrinsic criteria) was supported $(\beta=.42$, $t=6.08, p<.01$ ). H2b (social criteria) and $\mathrm{H} 2 \mathrm{c}$ (economic criteria) were not supported $(\beta=.03, t=.58, p=.56 ; \beta=-.06, t=-.84, p=.40$, respectively). Hypothesis 3 proposed that evaluation criteria (H3a: intrinsic criteria, H3b: social criteria, H3c: economic criteria) negatively influence consumer dissatisfaction with knitwear. Only $\mathrm{H} 3 \mathrm{~b}(\beta=-.11, t=-1.98$, $p<.05)$ was supported while H3a and H3c were not supported $(\beta=.29, t=4.56, p<.01$; $\beta=.12, t=1.58, p=.11$, respectively). Interestingly, intrinsic criteria had a significant, positive association with consumer dissatisfaction with knitwear, indicating that consumers who evaluate knitwear products based on intrinsic criteria are more likely to dissatisfy with knitwear.

\section{Moderating influence of knitwear involvement}

The second conceptual framework investigates how the overall paths between each evaluative criteria (intrinsic, social, and economic criteria) and satisfaction, and between

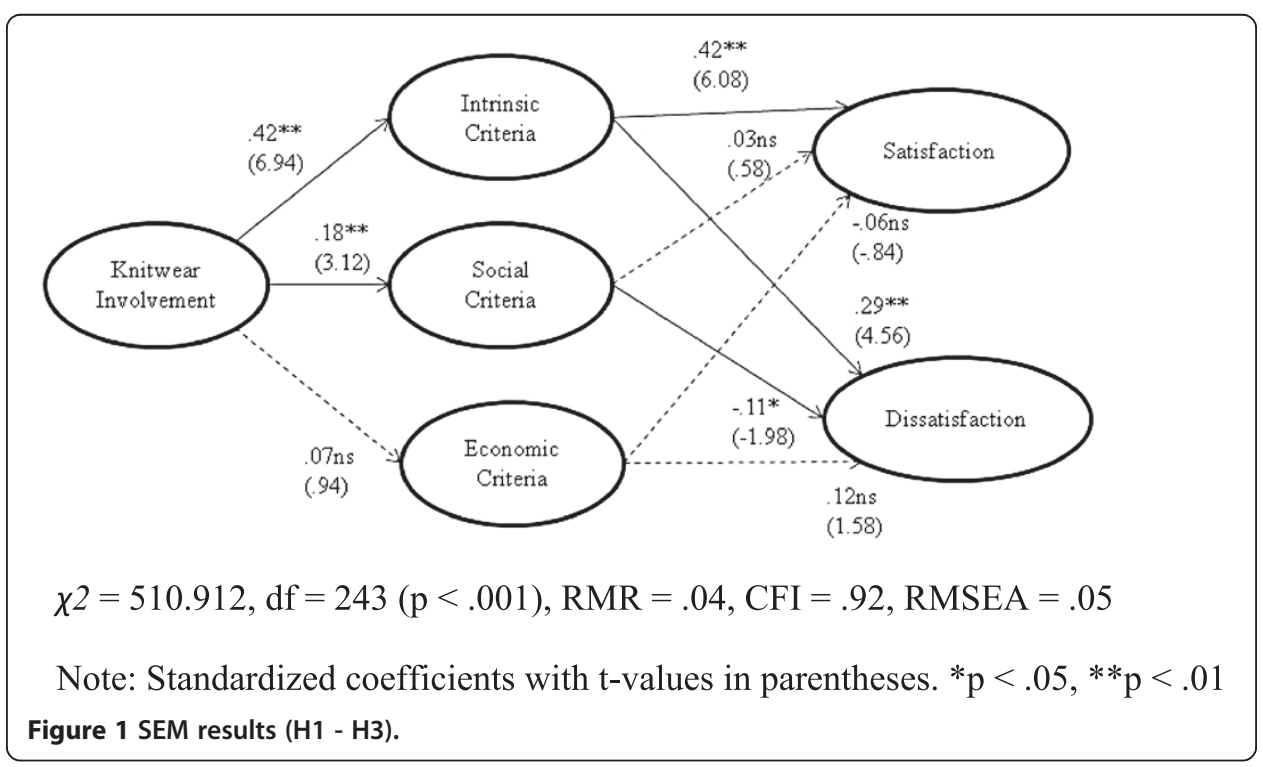


each criteria and dissatisfaction differ according to knitwear involvement. The sample was divided into two subgroups, high and low knitwear involvement groups, using Kmeans cluster analysis based on their knitwear involvement scores. Because of the use of multiple items to measure knitwear involvement and their differential contributions to the group differences, $\mathrm{K}$-means cluster analysis was used instead of median split-half to identify groups. The sample sizes of high and low knitwear involvement groups were 200 and 182, respectively.

Multi-group SEM was performed to test the differences of the paths in the resulting two groups. As a result of the multi-group comparison, the fit indices for the unconstrained model and the invariant measurement weight model were not significantly different $(\Delta \chi 2=7.008, \Delta d f=15, p=.957)$, indicating that the measurement weights for the two involvement groups were not different. When the invariant measurement weight model and the invariant structural weight model were compared, the fit indices were significantly reduced and $\chi^{2}$ difference was significant $\left(\Delta \chi^{2}=14.700, \Delta d f=6, p<.05\right)$. This result indicates that the structural weights of the models for the two groups were significantly different, supporting the moderating effect of the knitwear involvement. Chi-squared tests of differences between the high and low knitwear involvement group were conducted with the partial invariance model as the baseline model. A series of comparisons between the baseline model and the restricted model was performed where the hypothesized path coefficient was constrained to be equal for both high and low knitwear involvement groups in each comparison.

To compare the proposed paths according to knitwear involvement, two separate models for high and low knitwear involvement groups were compared using SEM (Figure 2). For the high involvement group, intrinsic criteria significantly influenced satisfaction $(\beta=.36, t=4.01, p<.01)$. Economic criteria had a significant, positive association with dissatisfaction, different from the hypothesized direction $(\beta=.26, t=2.67$, $p<.01)$. Similar to the high involvement group, the low involvement group showed a significant, positive relationship between intrinsic criteria and satisfaction $(\beta=.26, t=$ $2.67, p<.01)$. Different from the high involvement group and the hypothesized direction of the relationship, intrinsic criteria significantly, positively influenced dissatisfaction in the low involvement group $(\beta=.44, t=3.96, p<.01)$.

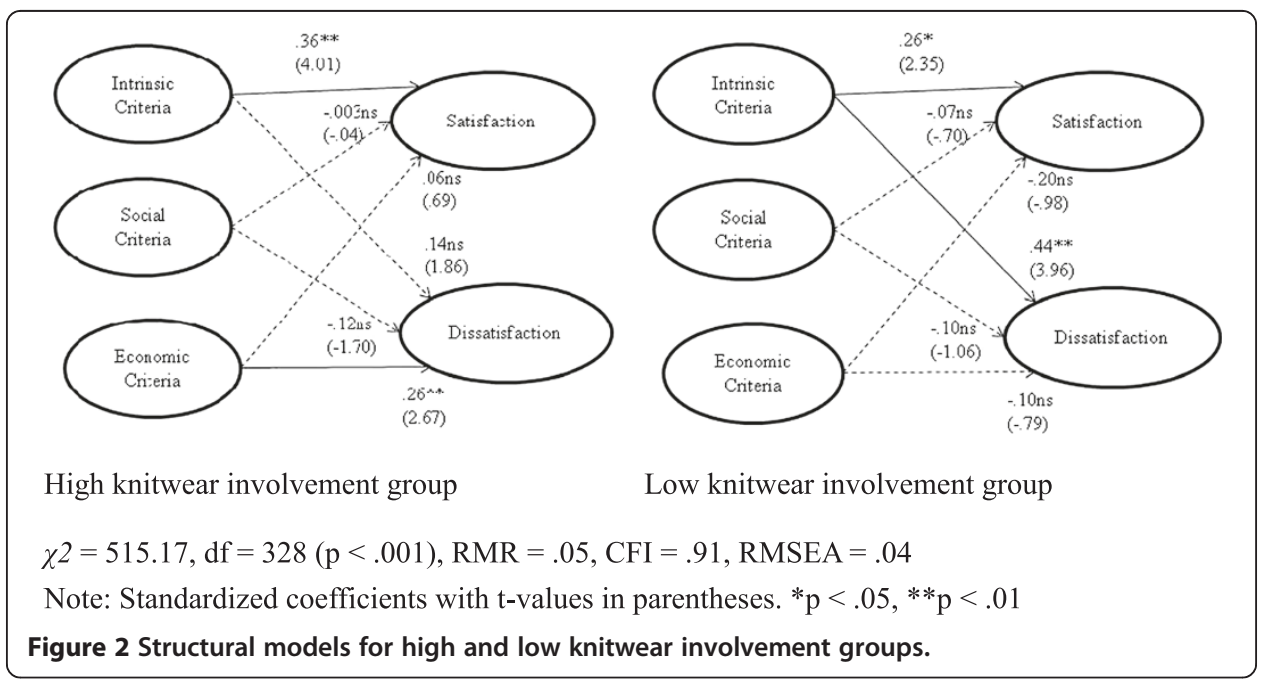


Hypothesis 4 was partially supported. Only two relationships (H4d: intrinsic criteria and dissatisfaction, H4f: economic criteria and dissatisfaction) were moderated by knitwear involvement, supporting H4d and H4f. The relationship between intrinsic criteria and dissatisfaction was significantly stronger in the low knitwear involvement group than in the high knitwear involvement group ( $\chi^{2}$ diff. $\left.=3.91, p<.05\right)$; the moderating effect of low involvement on the association between intrinsic criteria and dissatisfaction $(\beta=.44, t=3.96, p<.01)$ was stronger than that of high involvement $(\beta=.14, t=1.86$, $p>$.05). The relationship between economic criteria and dissatisfaction was significantly stronger in the high knitwear involvement group than in the low knitwear involvement group ( $\chi 2$ diff. $=6.83, p<.05)$; the moderating effect of high involvement on the association between economic criteria and dissatisfaction $(\beta=.26, t=2.67, p<.01)$ was stronger than that of low involvement $(\beta=.10, t=.79, p>.05)$.

\section{Discussion}

Employing two conceptual frameworks, the present study examined knitwear involvement as an antecedent of evaluative criteria, satisfaction, and dissatisfaction and as a moderator affecting the relationships among evaluative criteria, satisfaction, and dissatisfaction. In the study, three types of evaluative criteria were investigated; intrinsic, social, and economic criteria. In line with O'Cass and Choy (2008) and Tsiotsou (2006), the effect of involvement as an antecedent on evaluative criteria was supported: knitwear involvement was a significant antecedent of intrinsic criteria and social criteria used for knitwear evaluation. When consumers were highly involved in knitwear products, they were shown as more likely to perceive the importance of design, color, fabric, comfort, fit, workmanship, advertising, model, country-of-origin, and brand in product evaluation. However, contrary to the proposed hypothesis, the effect of knitwear involvement on economic criteria was not supported. Economic criteria in this study was measured by, discount level and good price. There could be another determinant of economic criteria other than consumer involvement in knitwear products, such as price consciousness, price sensitivity, or consumer characteristics. Price may a complex issue relevant to personal aspects. For example, innovativeness, brand parity, and brand loyalty were found to mediate the influence of involvement on price sensitivity (Ramirez and Goldmith 2009). Consumers with high innovativeness, involvement, and loyalty are relatively more price insensitive than other consumers (Ramirez and Goldmith 2009; Goldsmith et al. 2010). Also, in the study of Lee and Park (2006a), which categorized apparel involvement into interest, trend, and symbolic importance, only symbolic importance positively influenced economic criteria, indicating that not all the elements of apparel involvement resulted in a salient evaluation of economic criteria.

The importance of evaluation criteria was hypothesized to positively influence consumer satisfaction with knitwear and negatively influence consumer dissatisfaction. Satisfaction was affected by only an evaluation of intrinsic criteria, not social and economic criteria. Consumers who importantly considered design, color, fabric, comfort, and workmanship (intrinsic criteria) were satisfied with knitwear products. S d quality. Regarding the relationship between evaluative criteria and consumer dissatisfaction, only social criteria negatively influenced consumer dissatisfaction, while intrinsic criteria had a significant, positive association with consumer dissatisfaction. Interestingly, when consumers considered intrinsic criteria importantly to evaluate 
knitwear products, they were shown as more likely to satisfy as well as dissatisfy with the products. Especially for knitwear, consumers purchase and wear the products because of its soft texture, stretch, comfort, and insulation (Ryu 2002). Knitwear is much more sensitive to quality and workmanship compared to other apparel product categories (Hong et al. 2002). Thus, when evaluating the knitwear products, the importance may be in its design, color, fabric, comfort, and workmanship. The enhanced perceived importance of intrinsic criteria by consumers may make them deliberately evaluate the products based on objective information, which makes them more likely to satisfy or dissatisfy. Also, there may be other variables to explain satisfaction and dissatisfaction better than evaluative criteria such as expectation and disconfirmation (Bearden and Teel 1983; Oliver 1993).

In the second conceptual framework, knitwear involvement was a significant moderator of evaluative criteria. High and low involvement groups significantly differed in intrinsic criteria-dissatisfaction and economic criteria-dissatisfaction relations; when consumers were lowly involved in knitwear products than when they were highly involved, intrinsic criteria positively influenced consumer dissatisfaction more strongly; when consumers had high knitwear involvement than when they had low involvement, economic criteria positively influenced dissatisfaction more strongly. For both high and low involvement groups, intrinsic criteria had a significant impact on satisfaction, indicating the importance of intrinsic attributes while high involvement group showed bigger positive effect of intrinsic criteria on satisfaction. However, the importance of social and economic criteria to consumer satisfaction were not supported for both involvement groups, reassuring the relative importance of design, color, fabric, comfort, and workmanship of knitwear products, as a quality-sensitive product category (Hong et al. 2002). Regarding the relationship between evaluative criteria and dissatisfaction, in high involvement group, consumers who considered economic criteria as important were likely to dissatisfy with knitwear products, while the relationship was not significant in low involvement group. When consumers are highly involved, that is, have more interest, personal importance, and enjoyment in knitwear, discount or price seems to become more important to their dissatisfaction. Contrary to high involvement group, in low involvement group, consumers who put more emphasis on intrinsic criteria tended to dissatisfy with knitwear products. As mentioned before, for both high and low involvement groups, satisfaction and dissatisfaction may be explained well with expectation and disconfirmation (Bearden and Teel 1983; Oliver 1993) or congruity between expectation and outcome (Chon and Olsen 1991) rather than evaluative criteria though evaluative criteria have previously been researched to explain satisfaction and dissatisfaction.

\section{Theoretical and managerial implications}

The present study provides theoretical contributions to the knitwear literature by revealing the role of knitwear involvement as an antecedent of evaluative criteria and a moderator of the evaluative criteria-satisfaction and evaluative criteria-dissatisfaction relations. Though the demand and importance of knitwear products are continuously growing in apparel industry, research focused on knitwear products was little examined in the context of consumer involvement and evaluative criteria. Thus, the primary contribution of this research is adding literature to knitwear research especially for 
understanding product evaluation dynamics of consumers by employing explanation variables such as involvement, evaluative criteria, satisfaction, and dissatisfaction. The previous studies are limited to various topics of knitwear products including designer's artworks, patternmaking, brand, attribute evaluation, and consumption pattern (Han and Kim 2000; Lee et al. 2007); thus, the current study broadens our understanding of attribute evaluation or evaluative criteria of specific attributes by examining consumer involvement as an influential variable in the context of knitwear categories, which has been less tested empirically. Also, the current study was the first that tested three types of evaluative criteria including intrinsic, social, and economic criteria to judge knitwear products.

The study also offers important managerial implications to knitwear product manufacturers, marketers, and retailers by giving information about consumer perception of knitwear involvement and evaluative criteria. The results of the study suggest that marketers and retailers need to know the level of their consumers' involvement in their knitwear products in order to understand how important they consider intrinsic and social criteria when purchasing their products. They could take a survey and develop a consumer profile for better understating the involvement level of their target consumers. Also, knitwear marketers and retailers need to carefully develop intrinsic and social attributes by offering satisfiable intrinsic attributes of their products (design, color, fabric, comfort, fit, and workmanship) and social attributes of their products (advertising, model, country-of-origin, and brand), because these significantly influence consumer dissatisfaction with their products. For example, they can provide good quality of knitwear products in design, fabric, and comfort while employing celebrity models for their advertisements. Manufacturers, marketers, and retailers should give extra focus on delivering flattering design, color, fabric, comfort, and fine workmanship of knitwear products (intrinsic attributes) in order to efficiently improve consumer satisfaction; the importance of intrinsic criteria is emphasized for both highly involved and lowly involved consumers.

\section{Limitation and future study}

While the current study adds valuable contributions to the literature and provides good insights to marketers and retailers, there are several limitations. The present study is focused on a specific apparel category, knitwear; thus, this limits a generalization of the results of the current study to other apparel products. Also, most of the sample used in the study was highly educated with college graduates or higher, limiting a generalization of the findings. Future study should employ unbiased sample in terms of education for a generalization of the result to a bigger population. The study examined only three types of evaluative criteria including intrinsic, social, and economic criteria. Future researchers need examine various types of evaluative criteria using different categorization of evaluative criteria from the categorization used in the current study. Regarding the involvement variable, the present research examined a broad concept of consumer involvement assessed by perceived importance, interest, and enjoyment in knitwear products and advertising, called knitwear involvement. Researchers could identify various types of consumer involvement depending on an entity of involvement, for example, product, purchase decision, consumption, and advertising involvement (O'Cass 2000), and use them to investigate consumer behavior for knitwear products. 
Moreover, evaluative criteria were not well explained with satisfaction and dissatisfaction. Thus, future study needs to explore other determinants to better explain satisfaction and dissatisfaction, for example, expectation and disconfirmation (Bearden and Teel 1983; Oliver 1993) or congruity between expectation and outcome (Chon and Olsen 1991). Further research on a relationship between various criteria and outcome variables (e.g., purchase behavior, approach, and avoidance) will also be helpful to fully understand a knitwear market and consumer. Lastly, to examine the moderation effect, the present study conducted the multi-group SEM, but a future study can examine the analysis of interactive effect of involvement and criteria on satisfaction and dissatisfaction.

Competing interests

The authors declare that they have no competing interests.

\section{Authors' contributions}

SWJ and KL contributed to conception and design of the study. SWJ analyzed the data and drafted the manuscript. KL contributed to the acquisition of data and guidance. Both authors read and approved the final manuscript.

\section{Author details}

${ }^{1}$ Department of Clothing and Textiles, Sangmyung University, 20 Hongjimun2-gil, Jongno-gu, Seoul 110-743, Korea.

${ }^{2}$ Department of Clothing and Textiles, Hanyang University, 222 Wangsimni-ro, Seongdong-gu, Seoul 133-791, Korea.

Received: 27 January 2014 Accepted: 6 June 2014

Published online: 10 July 2014

\section{References}

Anderson, JC, \& Gerbing, DW. (1988). Structural equation modeling in practice: A review and recommended two-step approach. Psychological Bulletin, 103(3), 411-423.

Arnold, MJ, \& Reynolds, KE. (2003). Hedonic shopping motivations. Journal of Retailing, 79(2), 77-95.

Bagozzi, R, \& Yi, Y. (1988). On the evaluation of structural equation models. Journal of the Academy of Marketing Science, 16(1), 74-94.

Bearden, WO, \& Teel, JE. (1983). Selected determinants of consumer satisfaction and complaint reports. Journal of Marketing Research, 20, 21-28.

Celsi, RL, \& Olson, JC. (1988). The role of involvement in attention and comprehension processes. Journal of Consumer Research, 15, 210-224.

Chae, MH, Black, C, \& Heitmeyer, J. (2006). Pre-purchase and post-purchase satisfaction and fashion involvement of female tennis wear consumers. International Journal of Consumer Studies, 30(1), 25-33.

Chon, K, \& Olsen, MD. (1991). Functional and symbolic congruity approaches to consumer satisfaction/dissatisfaction in consumerism. Journal of the International Academy of Hospitality Research, 3(1), 1-25.

Corfman, KP. (1991). Comparability and comparison levels used in choices among consumer products. Journal of Marketing Research, 28(3), 368-374.

Day, RL. (1983). The next step: Commonly accepted constructs for satisfaction research. In RL Day \& KH Hunt (Eds.), International fare in consumer satisfaction and complaining behavior (pp. 113-117). Bloomington, IN: Indiana University.

Day, RL. (1984). Modeling choice among alternative responses to dissatisfaction. In TC Kinnear (Ed.), Advances in consumer research, 11 (pp. 496-499). Ann Arbor, MI: Association for Consumer Research.

Dickson, PR. (1982). Person-situation: Segmentation's missing link. Journal of Marketing, 46(4), 56-64

Eckman, M, Damhorst, ML, \& Kadolph, SJ. (1990). Toward a model of the in-store purchase decision process: Consumer use of criteria for evaluating women's apparel. Clothing and Textile Research Journal, 8(2), 13-22.

Engel, JF, Blackwell, RD, \& Miniard, PW. (1995). Consumer behaviour (8th ed.). Fort Worth, TX: Dryden Press.

Fiore, AM, \& Damhorst, ML. (1992). Intrinsic cues as predictors of perceived quality of apparel. Journal of Consumer Satisfaction, Dissatisfaction and Complaining Behavior, 5, 168-178.

Forney, JC, Park, EJ, \& Brandon, L. (2005). Effects of evaluative criteria on fashion brand extension. Journal of Fashion Marketing and Management, 9(2), 156-165.

Gensch, DH, \& Javagli, RG. (1987). The influence of involvement on disaggregate attribute choice models. Journal of Consumer Research, 14(1), 71-82.

Giese, JL, \& Cote, JA. (2000). Defining consumer satisfaction. Academy of Marketing Science Review, Retrieved July 30, 2013, from http://amsreview.org/articles/giese01-2000.pdf.

Goldsmith, RE, Kim, D, Flynn, LR, \& Kim, W. (2010). Price sensitivity and innovativeness for fashion among Korean consumers. The Journal of Social Psychology, 145(5), 501-508.

Hair, JF, Willian, CB, Babin, BJ, \& Anderson, RE. (2009). Multivariate data analysis (7th ed.). Upper Saddle River, NJ: Prentice-Hall.

Han, S, \& Kim, M. (2000). Knitwear consumers' demographic characteristics and evaluation criteria. The International Journal of Costume Culture, 3(2), 136-146.

Hong, B, Lee, E, \& Kim, K. (2002). The analysis of knit wear purchaser's behavior of the women in their twentieth and thirtieth. Journal of the Korean Society of Clothing and Textiles, 26(7), 1055-1065. 
Hsu, H, \& Burns, LD. (2002). Clothing evaluative criteria: A cross-national comparison of Taiwanese and United States consumers. Clothing and Textiles Research Journal, 20, 246-252.

Huang, M. (2006). Flow, enduring, and situational involvement in the web environment: A tripartite second-order examination. Psychology \& Marketing, 23(5), 383-411.

Jin, B, Park, JY, \& Ryu, JS. (2010). Comparison of Chinese and Indian consumers' evaluative criteria when selecting denim jeans: A conjoint analysis. Journal of Fashion Marketing and Management, 14(1), 180-194.

Kleine, RB. (1998). Principles and practice of structural equation modeling. New York, NY: Guilford.

Korean Apparel Industry Association. (2010). The competition analysis \& leading strategy in knitted apparel industry 2010. Retrieved July 30, 2013, from http://kaia.or.kr/board/publish/view/sfl/wr_subject.wr_content/stx/.EB.8B.88. ED.8A.B8/wr_id/8507.

Lee, M, \& Burns, LD. (1993). Self-consciousness and clothing purchase criteria of Korean and United States college women. Clothing and Textiles Research Journal, 11(4), 32-40.

Lee, J, \& Park, J. (2006a). The effect of consumer's objective knowledge, subjective knowledge and involvement of apparel on product attribute evaluation. Journal of the Korean Society of Clothing and Textiles, 30(5), 818-828.

Lee, K, \& Park, J. (2006b). Criteria of evaluating clothing and web service on Internet shopping mall related to consumer involvement. Journal of the Korean Society of Clothing and Textiles, 30(12), 1747-1758.

Lee, W, Yun, T, \& Lee, B. (2005). The role of involvement in country-of-origin effects on product evaluation. Journal of International Consumer Marketing, 17(2-3), 51-72.

Lee, Y, Kim, Y, Kim, M, Lee, Y, Youn, S, \& Lee, K. (2007). Consumer age group differences in knitwear consumption behavior. The Research Journal of the Costume Culture, 15(2), 284-298.

Mano, H, \& Oliver, RL. (1993). Assessing the dimensionality and structure of the consumption experience: Evaluation, feeling, and satisfaction. Journal of Consumer Research, 20(3), 451-466.

Mittal, B. (1989). Must consumer involvement always imply more information search? Advances in Consumer Research, $16,167-172$.

Mittal, V, Kumar, P, \& Tsiros, M. (1999). Attribute-level performance, satisfaction, and behavioral intentions over time: A consumption-system approach. Journal of Marketing, 63, 88-101.

O'Cass, A. (2000). An assessment of consumers product, purchase decision, advertising and consumption involvement in fashion clothing. Journal of Economic Psychology, 21, 545-576.

O'Cass, A, \& Choy, E. (2008). Studying Chinese generation Y consumers' involvement in fashion clothing and perceived brand status. Journal of Product \& Brand Management, 17(5), 341-352.

Oliver, RL. (1993). Cognitive, affective, and attribute bases of the satisfaction response. Journal of Consumer Research, 20(3), 418-430.

Oliver, RL. (1997). Satisfaction: A behavioral perspective on the consumer. New York, NY: The McGraw-Hill Companies, Inc.

Ong, FS, Kitchen, PJ, \& Chew, SS. (2010). Marketing a consumer durable brand in Malaysia: A conjoint analysis and market simulation. Journal of Consumer Marketing, 27(6), 507-515.

Park, Y. (2012). A study on purchase appraisal standard and post-purchase satisfaction of natural dyeing products. Journal of Korean Society for Clothing Industry, 14(1), 64-74.

Park, N, Kim, M, Moon, Y, Seo, M, Seo, MJ, \& Lee, K. (2007a). Purchasing behavior and product evaluation criteria of knitted apparel consumers. Journal of the Korean Society of Clothing and Textiles, 31(7), 1064-1074.

Park, DH, Lee, J, \& Han, I. (2007b). The effect of on-line consumer reviews on consumer purchasing intention: The moderating role of involvement. International Journal of Electronic Commerce, 11(4), 125-148.

Ramirez, E, \& Goldmith, RE. (2009). Some antecedent of price sensitivity. The Journal of Marketing Theory and Practice, 17(3), 199-214.

Ryu, K. (2002). A study on the wearer's perception for the improvement of knit wear quality: A qualitative approach. The Research Journal of the Costume Culture, 10(3), 236-247.

Suh, JC, \& Yi, YJ. (2006). When brand attitudes affect the customer satisfaction-loyalty relation: The moderating role of product involvement. Journal of Consumer Psychology, 16(2), 145-155.

Swan, JE, \& Combs, LJ. (1976). Product performance and consumer satisfaction: A new concept. Journal of Marketing, $40,25-33$.

Swoboda, B, Haelsig, F, Schramm-Klein, H, \& Morschett, D. (2009). Moderating role of involvement in building a retail brand. International Journal of Retail \& Distribution Management, 37(11), 952-974.

Tsiotsou, R. (2006). The role of perceived product quality and overall satisfaction on purchase intentions. International Journal of Consumer Studies, 30(2), 207-217.

Westbrook, RA, \& Oliver, RP. (1991). The dimensionality of consumption emotion patterns and consumer satisfaction. Journal of Consumer Research, 18, 84-91.

Yeo, E, \& Rhee, Y. (1996). A study of post-purchase clothing evaluative criteria: The relationships among clothing satisfaction, brand attitude, repurchase intention. Journal of the Korean Society of Clothing and Textiles, 20(6), 1027-1038.

Yi, Y. (1990). A critical review of consumer satisfaction. In VA Zeithaml (Ed.), Review of marketing (pp. 68-123). Chicago, IL: American Marketing Association.

doi:10.1186/s40691-014-0009-2

Cite this article as: Jeong and Lee: Impact of evaluative criteria on satisfaction and dissatisfaction: identifying the role of knitwear involvement. Fashion and Textiles 2014 1:9. 